\title{
Preparation of frost atlas using different interpolation methods in a semiarid region of south of Iran
}

\author{
Shohre Didari • Shahrokh Zand-Parsa • \\ Ali Reza Sepaskhah • Ali Akbar Kamgar-Haghighi • \\ Davar Khalili
}

Received: 5 April 2011 / Accepted: 1 September 2011 / Published online: 24 September 2011

(C) The Author(s) 2011. This article is published with open access at Springerlink.com

\begin{abstract}
In this research, suitability of different kriging and inverse distance weighted (IDW) methods in estimating occurrence date of frost was evaluated. Data included minimum daily air temperature values from 27 meteorological stations of Fars province in southern Iran from 18 to 45 years. Data ranges of 0 to $-1.5,-1.5$ to -3 and below $-3^{\circ} \mathrm{C}$ were considered as mild, moderate and severe frost intensities, respectively. Starting with the first day of autumn, iso-occurrence days for the frost intensities and occurrence probabilities $(25 \%, 50 \%, 75 \%$ and $90 \%)$ were estimated using ordinary kriging, cokriging, residual kriging type 1 $(R K 1)$, residual kriging type 2 ( $R K 2)$, universal kriging and $I D W$ methods. In these models, the errors of estimated frost intensities at different probabilities were lowest in the $R K 2$ model, but lack of establishment of spatial structure due to long distance between stations caused the predictions not to be acceptable in some cases. In a proposed method (modified inverse distance weighted, $M I D W$ ), the trend between the first and last days of frost occurrence with earth elevation was removed, and the reminder values were estimated by $(I D W)$ method. Although, the errors for estimated frost dates by $M I D W$ and $R K 2$ methods were the same, but the MIDW method did not have the spatial establishment shortcoming. Furthermore, the simplicity and practicality of the MIDW method makes it a reasonable selection.
\end{abstract}

\section{Introduction}

Air temperature is the most important climatic characteristic, which determines the suitability of field crops due to its

Sh. Didari · Sh. Zand-Parsa $(\bowtie) \cdot$ A. R. Sepaskhah •

A. A. Kamgar-Haghighi • D. Khalili

Irrigation Department, Agricultural College, Shiraz University,

Shiraz, Iran

e-mail: zandparsa@yahoo.com relationship with the length of the growing period and evapotranspiration (Hudson and Wackernagel 1994). It classifies the plant species (Rubio et al. 2002) and specifies the vegetational pattern (Richardson et al. 2004). Air temperature is also considered as a limiting factor for plant growth. Many studies have focused on the determination of air temperature threshold for different plant growth processes and have categorized them according to resistance to frost (Blennow 1993, 1998; Ventskevich 1985). One of the issues that threatens agricultural production in different parts of the world is related to frost damages. In meteorology, frost refers to the condition when air temperature is less than a threshold value for a relatively short period of time. Every year, major economic losses incur due to frost damages to agricultural products all over the world. Consequently, assessment procedures for protection of agricultural products against frost stress are very important. There is no doubt that a complete prevention of frost damages to farms is impossible; however, it would be possible to minimize the frost damages with appropriate managements of cropping pattern based on occurred frost events.

Several researches have attempted to estimate air temperature at unmeasured points in order to predict frost occurrence. Francois et al. (1999) mapped frost risk for Bolivian Altiplano using NOAA satellite surface temperatures and long-term records of air temperature from 17 weather stations. Air temperature was measured in meteorological stations, which spread sparsely in the nonresidential and high elevation areas (Rolland 2002). Carrega (1995) noted the difficulty of estimation of weather parameters at ungauged sites. Hence, it seems necessary to determine the frost probability, or in other words, frost prediction in different areas and between the stations, to decrease damages of this phenomenon by employing different methods of frost protection (Dodson and Marks 
1997). Tait and Zheng (2002) prepared the maps of the first and last frost dates for the Otago region of New Zealand and mapped them using the minimum air temperature of climate stations, the Advanced Very High Resolution Radiometer satellite surface temperatures and the geographical variables of altitude, latitude, longitude, and distance to the sea from 1999 and 2000.

Various methods are being used for prediction of air temperature in ungauged sites with different precisions, but there is not a unique method suited to all locations. A large number of methods are available for interpolation, which are broadly categorized into the groups of deterministic and geostatistical methods. All of them rely on the similarity of nearby sample points. Deterministic techniques use the mathematical functions for interpolation. Inverse distance weighted method (IDW) is one of these techniques and has been used by researchers in cases where the weight of measured points were influenced inversely by their distance from the prediction location (George et al. 2008). Geostatistics relies on both statistical and mathematical methods. Geostatistics consist of different methods that are used under different conditions. Ordinary kriging (OK) is used when the mean of the interpolated data, is unknown but is constant (Johnston et al. 2001). Residual kriging (RK) and universal kriging (UK) are used when data have trend and cokriging $(\mathrm{CK})$ is used when there are not enough samples of the main variable, so, a secondary variable with available data is used for estimation.

Benavides et al. (2007) compared air temperature in a mountainous region using five geostatistical and two regression models for January (coolest month) and August (warmest month) in northern Spain. A regression model, which includes altitude, latitude, distance to the sea and solar radiance showed better results for both months. Noshadi and Sepaskhah (2005) applied ordinary kriging, residual kriging, and cokriging for the interpolation of long-term monthly and yearly computed reference crop potential evapotranspiration $(E T o)$ in southern Iran including Fars, Booshehr, Hormozgan, and Kohgilooye-Boyrahmad provinces. Although, residual kriging and cokriging both had acceptable results, but for reaching the minimum $R M S E$, the best method for estimation of monthly ETo was cokriging, except in April, May and September. This exception might be due to a greater fluctuation of ETo with the height in these months. CarreraHernandez and Gaskin (2007) analyzed the temporal variation of minimum and maximum air temperature and rainfall and their correlations with elevation in Mexico by using ordinary kriging, kriging with external drift, block kriging with external drift, ordinary kriging, and kriging with external drift in a local neighborhood, respectively. The results showed that using of elevation as a secondary variable improved interpolation of daily events even with low correlation among variables.
In Fars province in southern Iran, frost occurrence has over time caused many damages to agricultural products, a problem which in many cases can be alleviated by applying special management tools based on information of the first and last dates of frost occurrences. The purpose of this study was to evaluate the suitability of different kriging and inverse distance weighing methods in estimating occurrence date of frost at $25 \%, 50 \%, 75 \%$, and $90 \%$ probability in Fars province and preparation of the maps of isooccurrence days for different frost intensities and probability levels.

\section{Materials and methods}

\subsection{Study area}

Fars province is located in south of Iran, covering an area of $132,000 \mathrm{~km}^{2}$, which is $6.7 \%$ of total area of Iran. Its latitude extend from $27^{\circ} 3^{\prime}$ to $31^{\circ} 42^{\prime}$ north and longitude from $50^{\circ} 30^{\prime}$ to $55^{\circ} 38^{\prime}$ east. Zagros Mountains with the general direction of northwest-southeast are extended to Fars province, with general decrease in elevation from north to south. The topography map of Fars province is shown in Fig. 1, which varies from a height of 3,915 m (masl) in the north to $115 \mathrm{~m}$ (masl) in the south. Mean of absolute minimum air temperature (MAMT) and absolute minimum air temperature (AMT) for four stations in north, south, east, and west of study area are shown in Fig. 1.

In some years, the air temperature is reduced to a level that field, and horticulture crops are severely damaged due to frost occurrence. In the northern and central parts of the province, the blooming stage of fruit trees such as apples, pears, almonds, and cherries, and in central regions, maize and sorghum and citruses fruits were damaged in spring, autumn, and winter, respectively, in some years.

In order to prepare the frost atlas, daily minimum air temperature values were used. Following the recommended procedures (Reddy 1983), the values of minimum daily air temperature of 27 meteorological stations with more than 15 years of daily data were used. The data period of stations are shown in Table 1.

\subsection{Criteria of minimum air temperature}

The criteria for minimum air temperature can range between zero to $-1.5^{\circ} \mathrm{C},-1.5^{\circ} \mathrm{C}$ to $-3^{\circ} \mathrm{C}$, and less than $-3^{\circ} \mathrm{C}$, considered as mild, moderate, and severe frost intensities, respectively (Whiteman 1957; Rosenberg et al. 1983). The occurrence of starting and ending frost dates from the first of autumn for different air temperature ranges are identified in the stations for each year. The $25 \%, 50 \%, 75 \%$, and $90 \%$ occurrence probabilities for the starting and ending frost 
Fig. 1 Map of Iran and topographic map of Fars province with different meteorological stations, also, MAMT and AMT for four stations are shown in north, south, east, and west of study area

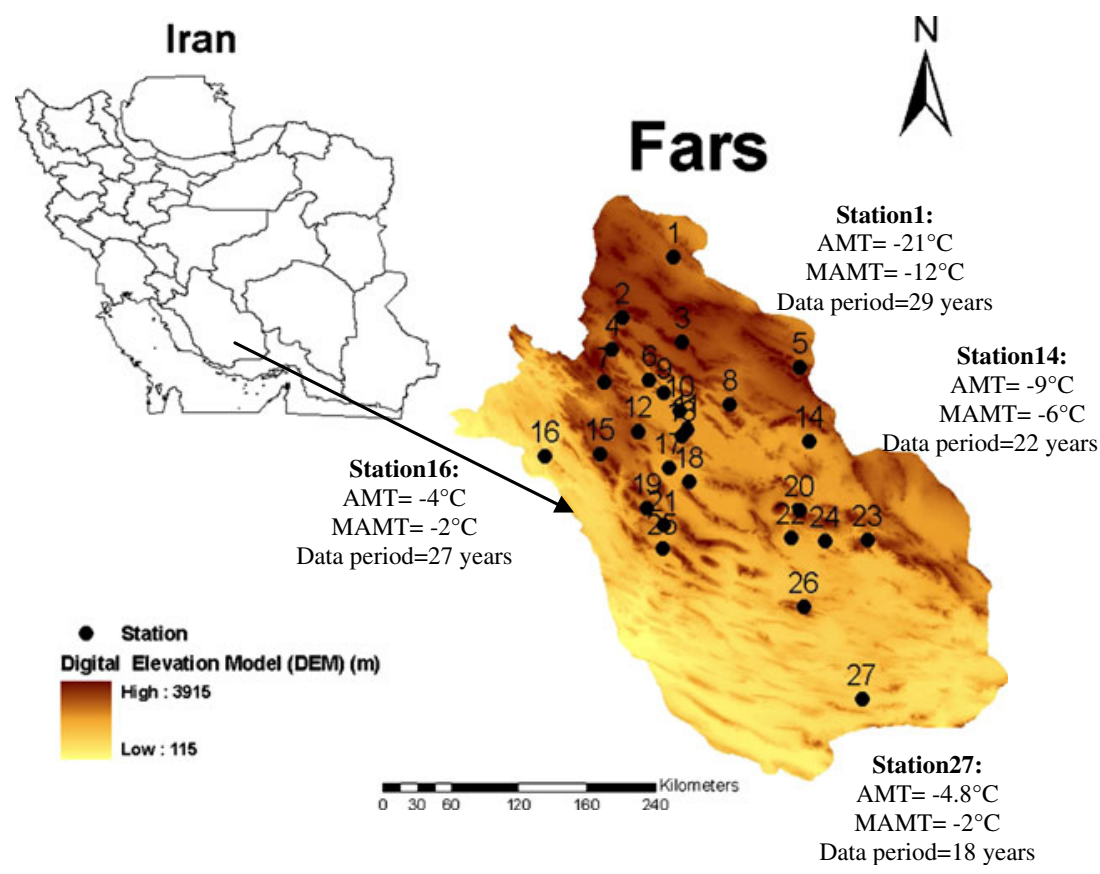

dates corresponding to each air temperature ranges and for each station were computed using the Weibull method as follows (Weibull 1951):

$P=\frac{m}{n+1}$

where $P$ is occurrence probability, $m$ is data rank, and $n$ is the number of data points.

For all frost intensities, the occurrence dates were sorted in an ascending order and the occurrence probability was computed for each station. In the south and southwest of the province, in some years, no frost occurred, which was mostly true for the moderate and severe intensities. For example, in station number 27 , there were 19 years of daily minimum air temperature records, which in 14 years, there were no severe frost and only for $75 \%$ and $90 \%$ of occurrence probabilities, the dates of beginning severe frosts were 78 and 128 days, respectively, after the first of autumn.

\subsection{Mapping procedures}

\subsubsection{Kriging}

In kriging method, for estimation of unknown values of a variable, first, spatial continuity should be controlled, and if it exists, then its value is estimated based on its correlation with other measured points. Spatial continuity means that adjacent samples are dependent upon a certain distance, and this dependency between samples can be presented by a mathematical model. The corresponding graphical illustration is called semivariogram. Semivariogram is a key tool in geostatistics which is used to describe variable continuity.
Experimental semivariogram $[\gamma(h)]$ is mean variance of the similarity between the measured values in locations $x$ and $x+$ $h$, as a function of distance between them $(h)$, as follows (Kitanidis 1997).

$\gamma(h)=\frac{1}{2 N(h)} \sum_{i=1}^{N(h)}\left(Z\left(x_{i}+h\right)-Z\left(x_{i}\right)\right)^{2}$

where $h$ is the vector between measured points, $Z\left(x_{i}\right)$ and $Z$ $\left(x_{i}+h\right)$ are the values of points $x_{i}$ and $x_{i}+h$, respectively, and $N(h)$ is total pair of points which is separated by distance $h$. If the values of semivariogram are different in different directions, it is anisotropic, and if it is plotted on twodimensional coordinate axes, it would be like an ellipse with the longer diameter called major range and its shorter diameter called minor range and the angle which the major range makes with the north coordinate is called anisotropy angle. In isotropic semivariogram, its value is the same in all directions. For expressing the semivariograms, some mathematical models are fitted to the measured values and their coordinates. Experimental semivariogram which consists of a set of discrete steps is transformed to continuous curve by mathematical models. In this study, seven different semivariogram models were used and their equations are presented in Table 2 (Johnston et al. 2001).

Kriging is based on "weighted moving average," and most researchers agree that it is the best linear unbiased estimator. To establish kriging unbiased condition, the sum of weighting coefficients must be equal to 1.0 :

$\sum_{i=1}^{n} \lambda_{i}=1.0$ 
Table 1 The elevation and occurred first and last frost dates of mild and sever frost intensities at $50 \%$ probability from first of autumn in the selected stations

\begin{tabular}{|c|c|c|c|c|c|c|}
\hline Station ID & Elevation (m) & $\begin{array}{l}\text { Data } \\
\text { period } \\
\text { (year) }\end{array}$ & $\begin{array}{l}\text { First day of } \\
\text { mild frost } \\
\text { records } \\
\text { (prob.50\%) }\end{array}$ & $\begin{array}{l}\text { Last day of } \\
\text { mild frost } \\
\text { records } \\
\text { (prob. } 50 \% \text { ) }\end{array}$ & $\begin{array}{l}\text { First day of } \\
\text { severe frost } \\
\text { records } \\
\text { (prob.50\%) }\end{array}$ & $\begin{array}{l}\text { Last day of } \\
\text { severe frost } \\
\text { records } \\
\text { (prob. } 50 \% \text { ) }\end{array}$ \\
\hline 1 & 2030 & 29 & 46 & 190 & 61 & 167 \\
\hline 2 & 2192 & 25 & 50 & 192 & 64 & 166 \\
\hline 3 & 2342 & 25 & 44 & 199 & 55 & 173 \\
\hline 4 & 1797 & 25 & 50 & 176 & 75 & 167 \\
\hline 5 & 2120 & 23 & 50 & 173 & 89 & 150 \\
\hline 6 & 1620 & 19 & 82 & 151 & 110 & 119 \\
\hline 7 & 2097 & 22 & 42 & 200 & 65 & 172 \\
\hline 8 & 1865 & 24 & 26 & 205 & 46 & 189 \\
\hline 9 & 1650 & 20 & 55 & 189 & 69 & 161 \\
\hline 10 & 1616 & 30 & 54 & 184 & 70 & 152 \\
\hline 11 & 1810 & 34 & 32 & 205 & 53 & 183 \\
\hline 12 & 2050 & 30 & 71 & 173 & 89 & 155 \\
\hline 13 & 1596 & 24 & 55 & 189 & 69 & 157 \\
\hline 14 & 1589 & 22 & 62 & 159 & 86 & 146 \\
\hline 15 & 2015 & 26 & 53 & 186 & 66 & 168 \\
\hline 16 & 847 & 26 & 92 & 152 & No severe frost & No severe frost \\
\hline 17 & 1488 & 45 & 65 & 160 & 88 & 132 \\
\hline 18 & 1490 & 21 & 88 & 146 & No severe frost & No severe frost \\
\hline 19 & 1700 & 23 & 47 & 175 & 63 & 162 \\
\hline 20 & 1610 & 19 & 48 & 174 & 65 & 159 \\
\hline 21 & 1585 & 25 & 60 & 189 & 69 & 138 \\
\hline 22 & 1288 & 40 & 75 & 157 & 93 & 111 \\
\hline 23 & 1419 & 25 & 89 & 146 & 104 & 112 \\
\hline 24 & 1388 & 18 & 62 & 168 & 94 & 143 \\
\hline 25 & 1376 & 21 & 107 & 132 & No severe frost & No severe frost \\
\hline 26 & 1158 & 25 & 78 & 149 & 72 & 96 \\
\hline 27 & 792 & 18 & 103 & 112 & No severe frost & No severe frost \\
\hline
\end{tabular}

where $\lambda_{i}$ is the weighted coefficient of the $i$ th point. Furthermore, estimation should be free from systematic error; therefore, variance of the estimation should be minimized. Kriging with regard to the characteristics of spatial structure can be one of the several methods; the ones used in this study will be described next.

\subsection{2 $\mathrm{OK}$}

This method is used for conditions when the mean of the data is unknown and is appropriate for most cases where the number of data is not enough for calculation of actual mean. The ordinary kriging $(\mathrm{OK})$ equation is as follows (Isaaks and Srivastava 1989):

$Z^{*}\left(x_{0}\right)=\sum_{i=1}^{n} \lambda_{i} \cdot Z\left(x_{i}\right)$ where $Z^{*}\left(x_{0}\right)$ is the estimated value in location $x_{0}, \lambda_{i}$ is the weighting coefficient related to $i$ th sample, $Z\left(x_{i}\right)$ is the measured value at $x_{i}$ and $n$ is the number of observation points. Variance of estimation in this case is:

$\sigma_{\mathrm{OK}}^{2}=\sum_{i=1}^{n} \lambda_{i} \gamma_{0 i}+\mu-\gamma_{00}$

where $\gamma_{00}$ is the average semivariogram corresponding to $h$ equal to zero, $\gamma_{0 i}$ is the average semivariogram corresponding to $h$ equal to the distance between the $i$ th observation point and point of interest and $\mu$ is the Lagrange multiplier.

\subsubsection{RK}

This method, which is known as ordinary kriging with external drift, is used when data have trend. In such 
Table 2 Equations of used different semivariogram models

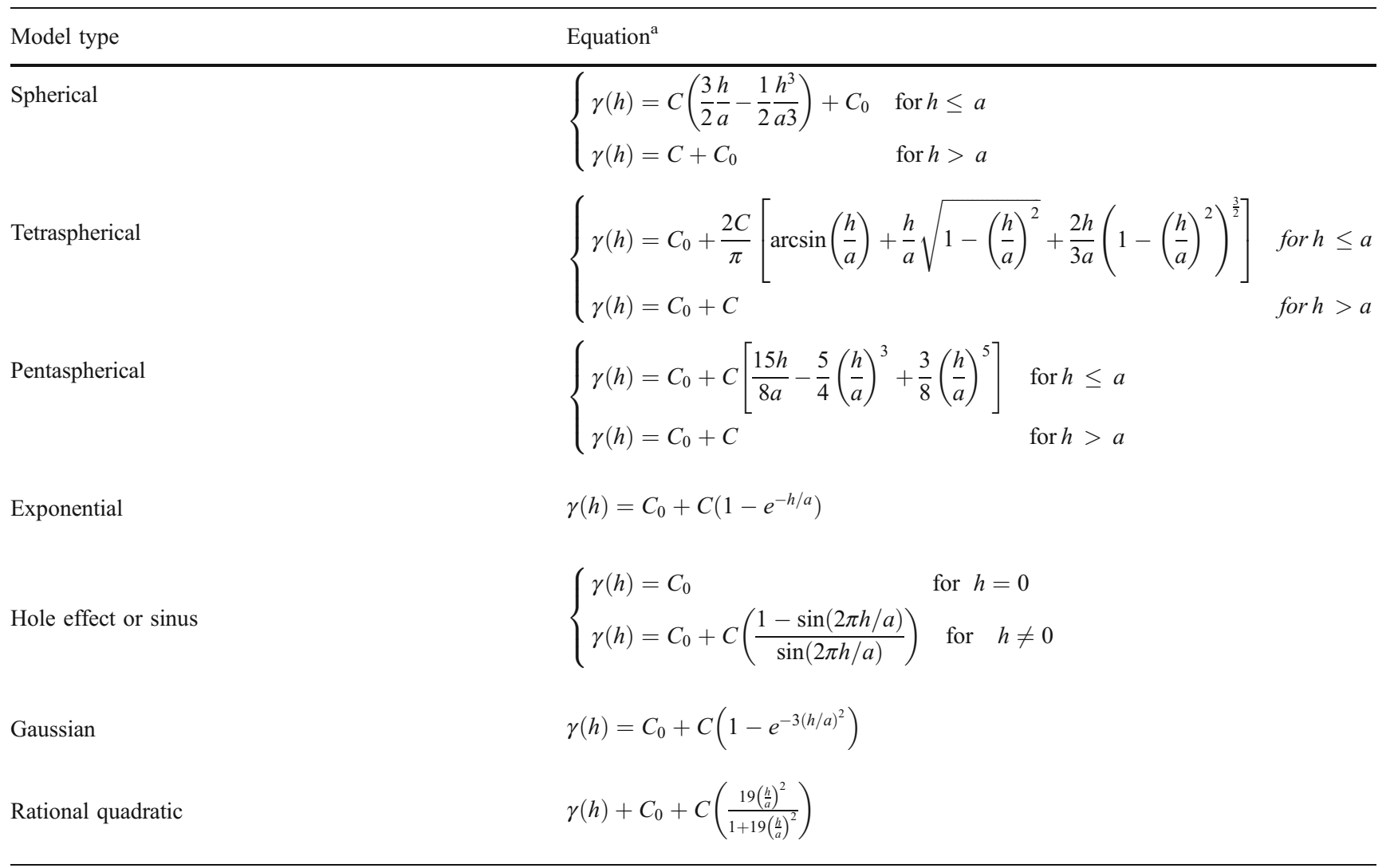

In these equations, $a$ is range, $C$ is partial sill, $C_{0}$ is Nugget of semivariogram, and $h$ is vector between the measured points

conditions, trend is modeled by linear or nonlinear functions and then the trend is removed by subtracting its values from the measured data. The residuals are estimated by ordinary kriging. Finally, the removed trend is added back to the result of estimation.

\subsubsection{RK1}

In this case, trend is removed by fitting a polynomial to the $x$ and $y$ coordinates, and the residuals are estimated by ordinary kriging. The equations of first- and second-order polynomials are as follows:

$Z\left(x_{i}, y_{i}\right)=\beta_{0}+\beta_{1} x_{i}+\beta_{2} y_{i} \quad$ First order

$$
\begin{aligned}
Z\left(x_{i}, y_{i}\right)= & \beta_{0}+\beta_{1} x_{i}+\beta_{2} y_{i}+\beta_{3} x_{i}^{2}+\beta_{4} y_{i}^{2} \\
& +\beta_{5} x_{i} y_{i} \quad \text { Second order }
\end{aligned}
$$

\subsubsection{RK2}

In this method, trend is removed by using an auxiliary variable (Wackernagel 1998; Chiles and Delfiner 1999), which in this study is elevation. First, a linear function of occurrence date for starting or ending of frost and site elevation is fitted to data. The trend or the differences between the predicted occurrence dates by this function and the observed data are removed, and the residuals are estimated by ordinary kriging. Finally, the removed trend is added back to the result of estimation.

\subsubsection{UK}

This method is also used when the data have trend and the removal of the trend and processing the residuals occur together as follows:

$Z_{\mathrm{UK}}^{*}\left(x_{0}\right)=\sum_{j=0}^{k} \sum_{i=1}^{n} a_{j} \lambda_{i} f_{j}\left(x_{i}\right)$

where $f_{j}(x)$ is the fundamental function which is determined based on the nature of the trend. In this study first-, second-, and third-order polynomials were used. The value of variance of universal kriging $\left(\sigma_{\mathrm{UK}}\right)$ is calculated as follows:

$\sigma_{\mathrm{UK}}^{2}=\sum_{i=1}^{n} \lambda_{i} \gamma_{0 i}+\sum_{j=1}^{k} \mu_{j} f_{j}\left(x_{0}\right)-\gamma_{00}$ 
Fig. 2 Daily minimum air temperature for stations 1 and 27 in $1995-2005$

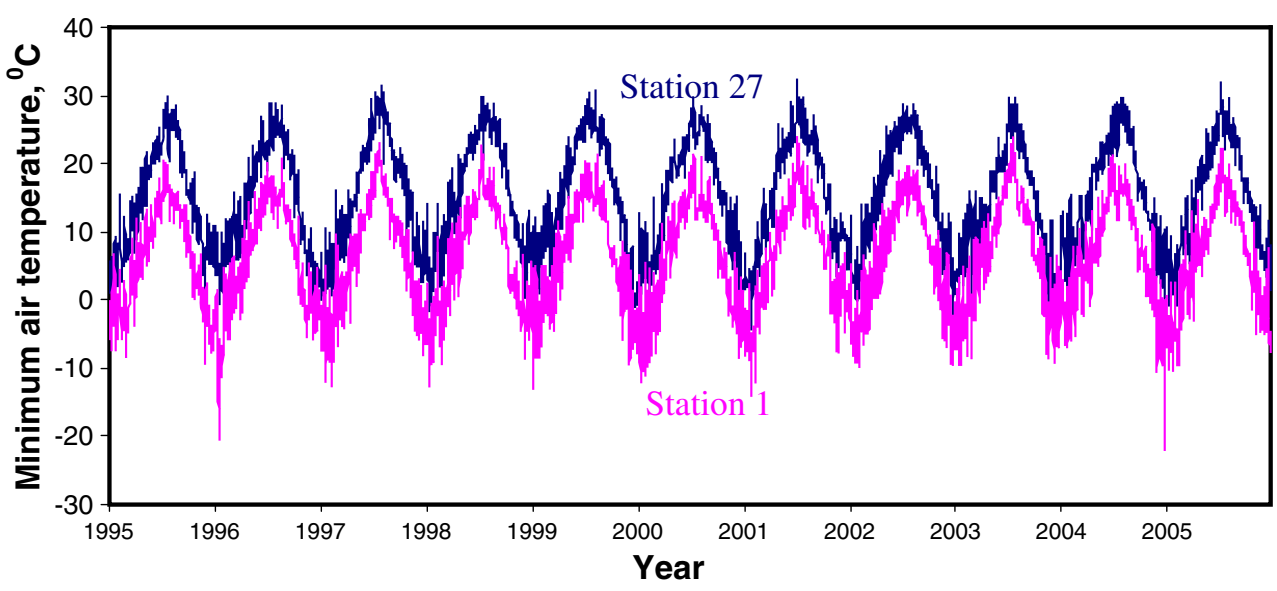

\subsubsection{CK}

This method is used where the main variable does not have enough data. In such cases, for estimation of main variable, a secondary variable with more available data is used (Goovaerts 1997). Cokriging estimator is the weighted linear combination of both primary and secondary variable values as follows:

$Z^{*}\left(x_{0}\right)=\sum_{i=1}^{n} \lambda_{i}^{1} Z\left(x_{i}\right)+\sum_{j}^{m} \lambda_{j}^{2} Y\left(x_{j}\right) \quad i=1,2, \ldots, n \quad, \quad j=1,2, \ldots, m$

where $Z\left(x_{i}\right)$ is the main variable, $Y\left(x_{i}\right)$ is the auxiliary variable, $\lambda_{i}^{1}$ and $\lambda_{j}^{2}$ are the main and auxiliary variable weights, respectively, which their sum should be equal to 1.0. For assigning appropriate weights, a cross variogram $[\gamma(Z Y) h]$ should be calculated as follows:

$\gamma(Z Y) h=\frac{1}{2 N(h)} \sum_{i=1}^{N(h)}\left[Z\left(x_{i}+h\right)-Z\left(x_{i}\right)\right] \cdot\left[Y\left(x_{i}+h\right)-Y\left(x_{i}\right)\right]$

Table 3 The values of $L F F D, F L F D$, and default values for non-frost occurrence, at moderate and severe intensities and different probabilities for all selected stations

\begin{tabular}{lccccc}
\hline $\begin{array}{l}\text { Intensity } \\
\text { probability (\%) }\end{array}$ & $\begin{array}{l}\text { Moderate } \\
25\end{array}$ & $\begin{array}{l}\text { Moderate } \\
50\end{array}$ & $\begin{array}{l}\text { Severe } \\
25\end{array}$ & $\begin{array}{l}\text { Severe } \\
50\end{array}$ & $\begin{array}{l}\text { Severe } \\
75\end{array}$ \\
\hline FDate (DAA) & $26-98$ & $36-109$ & $34-77$ & $46-110$ & $52-118$ \\
LFFD (DAA) & 98 & 109 & 77 & 110 & 118 \\
DVN (DAA) & 118 & 129 & 97 & 130 & 138 \\
LDAT (DAA) & $106-190$ & $84-199$ & $114-186$ & $96-189$ & $116-193$ \\
FLFD (DAA) & 106 & 84 & 114 & 96 & 116 \\
DVN (DAA) & 86 & 64 & 94 & 76 & 96 \\
\hline
\end{tabular}

FDate first dates of occurred frost range, DAA days after first of autumn, $D V N$ default value for date of non-frost occurrence, $L D A T$ last dates of occurred frost range, $L F F D$ latest of first frost date, $F L F D$ first of last frost date

\subsection{Selection of the most appropriate model}

After fitting different models to the empirical semivariogram, the most appropriate model should be determined. For this purpose, the Jack-knife method is used (Isaaks and Srivastava 1989). According to this method, each of the points with known data is removed, and then its value is estimated by one of the kriging methods. The differences between the values of measured and estimated by kriging are considered as Jack-knife errors. A number of statistical methods for error calculation are available, which compare different semivariogram models and different kriging methods. Estimation of variables should be unbiased and centered on the measured values; therefore, mean prediction error (ME) and standardized mean prediction error (MSE) should be near zero, as determined by the following relationships:

$\mathrm{ME}=\frac{\sum_{i=1}^{n}\left(Z^{*}\left(x_{i}\right)-Z\left(x_{i}\right)\right)}{n}$

$\operatorname{MSE}=\frac{\sum_{i=1}^{n}\left(Z^{*}\left(x_{i}\right)-Z\left(x_{i}\right)\right) / \sigma\left(x_{i}\right)}{n}$

where $\sigma\left(x_{i}\right)$ is the kriging standard error.

The value of ME corresponding to the $95 \%$ confidence interval of the two-tailed $t$ test with $n-2 d . f$. (ME 95\%) is computed as (Walpole et al. 1998):

$\mathrm{ME}_{95 \%}=\left(t_{(n-2) 95 \%} \times \mathrm{SE}\right)$

where $t_{(n-2)} 95 \%$ is two-tailed $t$ at $95 \%$ interval with $d . f .=n-$ 2 , and $S E$ is the standard error of the mean. The values of $t_{(n-2)} 95 \%$ are determined from two-tailed $t$ table. 
Table 4 The values of RMSE, at $50 \%$ probability at first, second, and third polynomial orders at some cases of kriging methods

\begin{tabular}{llllll}
\hline Time of frost & Kriging method & Intensity & \multicolumn{2}{l}{ Polynomial orders } & \\
\cline { 4 - 5 } & & & First & Second & Third \\
\hline \multirow{2}{*}{ First } & UK & Mild & 23.65 & NA & NA \\
& \multirow{2}{*}{ RK1 } & Severe & 17.69 & NA & NA \\
& & Mild & NA & NA & NA \\
& UK & Severe & 24.28 & 24.6 & NA \\
& \multirow{2}{*}{ Last } & Mild & 17.79 & 20.31 & 61.83 \\
& & Severe & 28.84 & NA & 84.05 \\
& & Mild & 17.22 & 17.39 & NA \\
& & Severe & 28.41 & NA & NA \\
\hline
\end{tabular}

Predictions should be close to the measured values; therefore, the root-mean-square prediction errors (RMSE) should be as small as possible:

RMSE $=\sqrt{\frac{\sum_{i=1}^{n}\left(Z^{*}\left(x_{i}\right)-Z\left(x_{i}\right)\right)^{2}}{n}}$

In an acceptable method, the estimation error should have normal distribution. Therefore, both the necessary and sufficient conditions for model credibility at 95\% confidence level are as follows (Kitanidis 1997):

$\operatorname{MSE}<\frac{2}{\sqrt{n-1}}$

$\mid(\text { RMSS })^{2}-1 \mid<\frac{2.8}{\sqrt{n-1}}$

Considering the 27 meteorological stations in this study, the conditions for acceptance of a model are: MSE $<0.392$ and $\mid(\text { RMSS })^{2}-1 \mid<0.549$.
In order to have a strong spatial structure, the fitted semivariogram model should be able to establish the following condition:

$\frac{C_{0}}{C+C_{0}}<\frac{1}{2}$

where $C$ and $C_{0}$ are partial sill and nugget of semivariogram, respectively. The method with the lowest RMSE is considered as a suitable method.

\subsection{IDW}

This method is based on the assumption of similarity between the close samples. To predict a value for any unmeasured location, surrounding sample will get a weight which is decreased with their distance from the prediction location:

$$
Z^{*}\left(x_{0}\right)=\sum_{i=1}^{n} \lambda_{i} Z\left(x_{i}\right)
$$

Table 5 The values of calculated RMSE (day) of different methods for different probabilities of occurrence the first and last days for mild frost intensity

\begin{tabular}{|c|c|c|c|c|c|c|c|c|}
\hline $\begin{array}{l}\text { Estimation } \\
\text { method }\end{array}$ & $\begin{array}{l}\text { First mild } \\
\text { frost }(25 \% \\
\text { Prob.) }\end{array}$ & $\begin{array}{l}\text { First mild } \\
\text { frost }(50 \% \\
\text { Prob.) }\end{array}$ & $\begin{array}{l}\text { First mild } \\
\text { frost }(75 \% \\
\text { Prob.) }\end{array}$ & $\begin{array}{l}\text { First mild } \\
\text { frost }(90 \% \\
\text { Prob.) }\end{array}$ & $\begin{array}{l}\text { Last mild frost } \\
\text { (25\% Prob.) }\end{array}$ & $\begin{array}{l}\text { Last mild frost } \\
(50 \% \text { Prob.) }\end{array}$ & $\begin{array}{l}\text { Last mild frost } \\
\text { ( } 75 \% \text { Prob.) }\end{array}$ & $\begin{array}{l}\text { Last mild frost } \\
\text { (90\% Prob.) }\end{array}$ \\
\hline OK & N.A. & 19 & 21 & 23 & 21 & 20 & 19 & 17 \\
\hline RK1 & N.A. & N.A. & 19 & 20 & 18 & 17 & 17 & N.A. \\
\hline RK2 & N.A. & 15 & 16 & 18 & 16 & 15 & 15 & 13 \\
\hline UK & 17 & 18 & 20 & 21 & 18 & 18 & 18 & 15 \\
\hline CK & 18 & 19 & 21 & 23 & 21 & 19 & 19 & 17 \\
\hline IDW & 17 & 19 & 21 & 23 & 20 & 19 & 18 & 17 \\
\hline
\end{tabular}

$O K$ ordinary kriging; $R K 1$ residual kriging type 1; $R K 2$ residual kriging type 2; $U K$ universal kriging; $C K$ cokriging; $I D W$ inverse distance weighting; N.A. not applicable 
Table 6 The values of calculated RMSE (day) of different methods for different probabilities of occurrence, for the first and last days for moderate frost intensity

\begin{tabular}{|c|c|c|c|c|c|c|c|c|}
\hline $\begin{array}{l}\text { Estimation } \\
\text { method }\end{array}$ & $\begin{array}{l}\text { First moderate } \\
\text { frost }(25 \% \\
\text { Prob.) }\end{array}$ & $\begin{array}{l}\text { First moderate } \\
\text { frost }(50 \% \\
\text { Prob.) }\end{array}$ & $\begin{array}{l}\text { First moderate } \\
\text { frost }(75 \% \\
\text { Prob.) }\end{array}$ & $\begin{array}{l}\text { First moderate } \\
\text { frost }(90 \% \\
\text { Prob.) }\end{array}$ & $\begin{array}{l}\text { Last moderate } \\
\text { frost }(25 \% \\
\text { Prob. })\end{array}$ & $\begin{array}{l}\text { Last moderate } \\
\text { frost }(50 \% \\
\text { Prob.) }\end{array}$ & $\begin{array}{l}\text { Last moderate } \\
\text { frost }(75 \% \\
\text { Prob.) }\end{array}$ & $\begin{array}{l}\text { Last moderate } \\
\text { frost }(90 \% \\
\text { Prob.) }\end{array}$ \\
\hline OK & 24 & N.A. & N.A. & N.A. & 27 & 28 & 21 & 19 \\
\hline RK1 & 21 & 21 & 23 & N.A. & 23 & 24 & 19 & 17 \\
\hline RK2 & 18 & 20 & 19 & 20 & 16 & N.A. & 15 & 13 \\
\hline UK & 22 & 22 & 22 & 26 & 24 & 24 & 19 & 16 \\
\hline $\mathrm{CK}$ & 24 & N.A. & N.A. & 26 & 26 & 26 & 21 & 19 \\
\hline IDW & 23 & 21 & 22 & 25 & 25 & 26 & 21 & 19 \\
\hline
\end{tabular}

$O K$ ordinary kriging; $R K 1$ residual kriging type I; $R K 2$ residual kriging type II; $U K$ universal kriging; $C K$ cokriging; $I D W$ inverse distance weighting; N.A. not applicable

where $n$ is the number of measured points which is effective in estimation, $\lambda_{i}$ is the weight that is assigned to each point calculated from the following relationship:

$\lambda_{i}=\frac{d_{i 0}^{-p}}{\sum_{i=1}^{n} d_{i 0}^{-p}} \quad \sum_{i=1}^{n} \lambda_{i}=1$

where $d_{i 0}$ is the distance between prediction location and measured points which is effective in estimation, $p$ is the weight reduction factor which decreases exponentially by increasing distance. Optimal amount of power $(p)$ is determined by minimizing the RMSE by Jack-knife method.

\section{Results and discussion}

\subsection{Occurred frost intensities}

Figure 1 shows the topography map of the Fars province along with locations of the weather stations data for some stations. Figure 2 depicts the daily air temperature for the far north and far south weather stations in the province during 1995-2005. As illustrated by Fig. 2, station 27 (in the south of province) had higher air temperature values compared to station 1 (in the north of province) throughout the year.

In the south and southwest of Fars province, no frost date were recorded in some years, and for preparation of frost atlas map, the no frost intensity incident was assigned a zero value. The default assignment values were estimated at different intensities and probability levels by using the following procedure:

1. For stations with frost occurrence, for the latest of first frost date $(L F F D)$ and the first of last frost date (FLFD) were determined at each intensity and probability level.

2. LFFD and FLFD were assumed the first and last possible dates of frost occurrence in the selected stations at each intensity and probability level in the province.

3. Default values of frost dates at non-frost points were estimated by adding and subtracting 20 days to $L F F D$ and FLFD, respectively, at each intensity and probabil-

Table 7 The values of calculated RMSE (day) of different methods for different probabilities of occurrence, for the first and last days for sever frost intensity

\begin{tabular}{|c|c|c|c|c|c|c|c|c|}
\hline $\begin{array}{l}\text { Estimation } \\
\text { method }\end{array}$ & $\begin{array}{l}\text { First severe } \\
\text { frost }(25 \% \\
\text { Prob.) }\end{array}$ & $\begin{array}{l}\text { First severe } \\
\text { frost }(50 \% \\
\text { Prob.) }\end{array}$ & $\begin{array}{l}\text { First severe } \\
\text { frost }(75 \% \\
\text { Prob.) }\end{array}$ & $\begin{array}{l}\text { First severe } \\
\text { frost }(90 \% \\
\text { Prob.) }\end{array}$ & $\begin{array}{l}\text { Last severe } \\
\text { frost }(25 \% \\
\text { Prob.) }\end{array}$ & $\begin{array}{l}\text { Last severe } \\
\text { frost }(50 \% \\
\text { Prob.) }\end{array}$ & $\begin{array}{l}\text { Last severe } \\
\text { frost }(75 \% \\
\text { Prob.) }\end{array}$ & $\begin{array}{l}\text { Last severe } \\
\text { frost }(90 \% \\
\text { Prob.) }\end{array}$ \\
\hline OK & 17 & N.A. & 21 & N.A. & 24 & 30 & 25 & 22 \\
\hline RK1 & 19 & 24 & 18 & 23 & 23 & 28 & 22 & 20 \\
\hline RK2 & 13 & 19 & N.A. & 16 & N.A. & 22 & 18 & 15 \\
\hline UK & 17 & 24 & 18 & 20 & 23 & 29 & 22 & 21 \\
\hline $\mathrm{CK}$ & 17 & N.A. & 21 & N.A. & 23 & 30 & 24 & 23 \\
\hline IDW & 17 & 24 & 20 & 20 & 23 & 28 & 25 & 21 \\
\hline
\end{tabular}

$O K$ ordinary kriging; $R K 1$ residual kriging type I; $R K 2$ residual kriging type II; $U K$ universal kriging; $C K$ cokriging; $I D W$ inverse distance weighting; N.A. not applicable 
Table 8 Values of $a$ and $b$ in Eq. 21 in different probabilities and intensities for first and last occurrence dates

\begin{tabular}{|c|c|c|c|c|}
\hline \multirow[t]{2}{*}{ Frost intensity and probability level, \% } & \multicolumn{2}{|l|}{ First frost } & \multicolumn{2}{|c|}{ Last frost } \\
\hline & a & $\mathrm{b}$ & a & $\mathrm{b}$ \\
\hline Mild, 25 & -0.0325 & 106.21 & 0.0503 & 79.663 \\
\hline Mild, 50 & -0.04 & 128.34 & 0.0471 & 93.816 \\
\hline Mild, 75 & -0.0448 & 144.73 & 0.0385 & 118.46 \\
\hline Mild, 90 & -0.0496 & 161.07 & 0.0404 & 127.76 \\
\hline Moderate, 25 & -0.049 & 146.09 & 0.07 & 31.301 \\
\hline Moderate, 50 & -0.03 & 120.34 & 0.0659 & 47.478 \\
\hline Moderate, 75 & -0.0462 & 158.38 & 0.0497 & 88.926 \\
\hline Moderate, 90 & -0.0566 & 186.38 & 0.0468 & 105.72 \\
\hline Severe, 25 & -0.0391 & 136.55 & 0.0631 & 29.045 \\
\hline Severe, 50 & -0.0445 & 156.08 & 0.0743 & 17.639 \\
\hline Severe, 75 & -0.0202 & 122.16 & 0.0602 & 56.699 \\
\hline Severe, 90 & -0.0435 & 173.6 & 0.0503 & 86.996 \\
\hline
\end{tabular}

ity level. With application of this method, the frost and non-frost points of the entire province were distinguishable. The resulted values were used for interpolation between the frost and non-frost points and are shown in Table 3.

4. After preparation of frost map, the areas with estimated occurrence of frost dates greater or smaller than $L F F D$ and FLFD were considered as non-frost occurring regions, respectively.

According to the results, all of the meteorological stations experienced mild frost for all of the probability levels, but some of the stations in the south and southwest did not experience moderate or severe frost. In the north of province, air temperature is lower than the south and southwest; hence, moderate and severe frost could occur. Generally, frost events begin November and terminate in April, in the selected stations. Table 1 shows the occurred first and last frost dates of mild and sever frost intensities at $50 \%$ probability.

\subsection{Comparison of different interpolation methods}

The first and last days of occurred frost from the first of autumn at different levels of probabilities were predicted by different methods of kriging and $I D W$ for the entire Fars province stations (27 meteorological stations). For prediction of the first and last dates of frost occurrence by residual kriging type 1 and universal kriging, the first- and secondorder polynomials were used for removing biases. Results showed that in most cases of intensities and probabilities, the second and third polynomial orders were not applicable and in other cases, the values of computed RMSE in first polynomial order was less than higher orders (Table 4). In different stations, the values of RMSE for predictions of first and last frost occurrence for mild, medium and severe frost intensities at different occurrence probabilities were prepared by Jack-knife method and result are shown in Tables 5, 6, and 7. According to these Tables, the values of computed RMSE, in the methods of RK2 are the lowest, RK1 and UK are in the next order and finally, $O K, C K$, and $I D W$ are relatively greater. Among these methods, because of the minimum RMSE values, the $R K 2$ is the best method for prediction of first and last days of frost occurrence date. In some cases from a statistical point of view, the relatively large distance between the station locations could be one reason causing low spatial structure (LI et al. 2007). However, due to lack of establishment of a strong spatial structure (Eq. 18), the predictions were not acceptable which
Fig. 3 Relationships between the site elevation and a $F O D$ from the first of autumn for mild frost at $50 \%$ probability and (b) $L O D$ from the first of autumn (22 or 23 of September) for mild frost at $50 \%$ probability
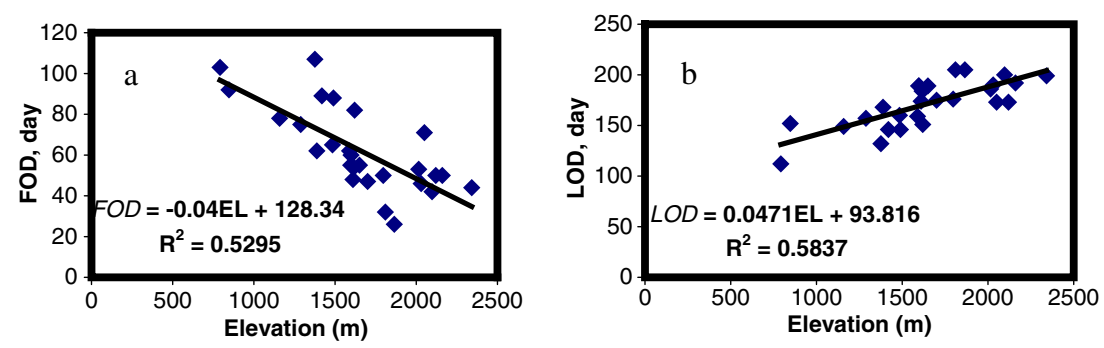
Table 9 The values of calculated RMSE (day) of MIDW method for different probabilities of occurrence, for first and last days for different frost intensities

\begin{tabular}{|c|c|c|c|c|c|c|c|c|c|c|}
\hline \multirow[t]{2}{*}{ Frost intensity } & \multicolumn{4}{|c|}{ Probability of first occurrence day (\%) } & \multirow[t]{2}{*}{ Mean } & \multicolumn{4}{|c|}{ Probability of last occurrence day (\%) } & \multirow[t]{2}{*}{ Mean } \\
\hline & 25 & 50 & 75 & 90 & & 25 & 50 & 75 & 90 & \\
\hline Mild & 14 & 15 & 16 & 18 & 16 & 17 & 15 & 15 & 13 & 15 \\
\hline Moderate & 17 & 20 & 19 & 20 & 19 & 16 & 21 & 16 & 14 & 17 \\
\hline Severe & 15 & 20 & 19 & 17 & 18 & 18 & 21 & 19 & 17 & 19 \\
\hline Mean & 15 & 18 & 18 & 18 & 18 & 17 & 19 & 17 & 15 & 17 \\
\hline
\end{tabular}

they are shown using "N.A." In $I D W$ method, the values of $R M S E$ are greater than those predicted by some of the kriging methods. Because of not considering the station elevation effects on air temperature, the frost occurrence day is not predicted correctly; therefore, the prediction of the first and last days of frost intensities are not estimated correctly.

\subsection{Modification of inverse distance weighted method}

Inverse distance weighted method has been modified. In the modified IDW, the trend of elevation on first or last days of frost occurrence at different intensities are calculated as follows:

$\mathrm{OFD}=a \times \mathrm{EL}+b$

where FOD ( $L O D)$ is occurrence of first (or last) day of frost, $E L$ is station elevation (m) and $a$ and $b$ are constant coefficients for different frost intensities and occurrence probability levels of first or last day of frost events. The values of $a$ and $b$ at different intensities and probabilities are shown in Table 8 and for $50 \%$ probability are shown in
Fig. 3. For higher elevation locations, frost occurs earlier and terminates later (Fig. 3).

The trend of the first and last days of frost occurrence were calculated using Eq. 21 and Table 8 using digital elevation model (DEM) of Fars province with resolution of $90 \mathrm{~m}$. Then, the trends were removed from the first and last frost occurrence dates for all of the meteorological stations and the associated residuals (actual residuals) were calculated using inverse distance weighting method. Finally, the removed trend was added back to the estimated residuals. As shown in Table 9, the RMSE values by the MIDW method are close to the RMSE of RK2 method (shown in Tables 5, 6, and 7), but since prediction of frost occurrence by the $M I D W$ is much easier, then this method is used for preparation of frost atlas in Fars province. The predicted first and last frost dates using the $M I D W$ method compared with recorded dates of frost for mild and severe intensities at $50 \%$ probability (Fig. 4). The values of $M E$ in all intensities and probabilities are smaller than $\mathrm{ME}_{95 \%}$; hence, they are not significant differences in $95 \%$ probability level with zero.
Fig. 4 Comparison between predicted first and last dates of frost using $M I D W$ method with recorded data at $50 \%$ probability at mild and severe intensities. NS is showing that $\mathrm{ME}$ is not significant differences with zero at $95 \%$ level
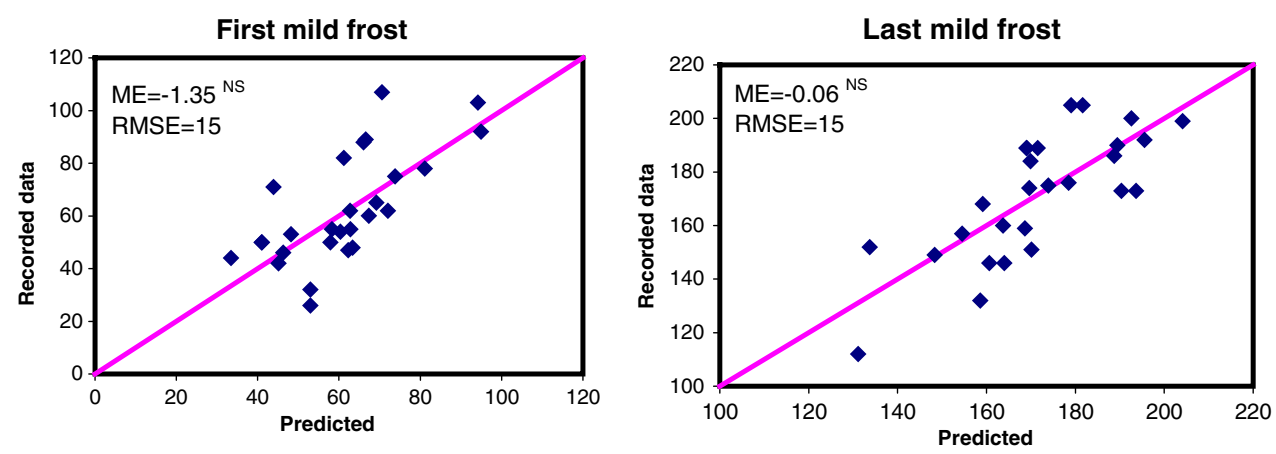

First severe frost

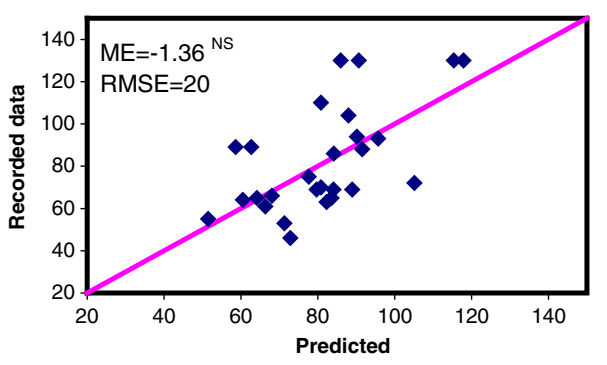




\subsection{Mapping procedure}

The maximum and minimum of station elevation at the selected meteorological stations are 2,342 and $792 \mathrm{~m}$, respectively, and for entire of Fars province are 3,915 and $115 \mathrm{~m}$, respectively. Therefore, when Eq. 21 is used throughout the study region, the results can be extrapolated for elevations higher than $2,342 \mathrm{~m}$ and lower than $792 \mathrm{~m}$, respectively. The lower elevation regions in the south and southeast of the province have warm weather so moderate and severe frost intensities occur rarely. In high elevation regions, some negative values were among the predictions for first day of frost, which means that frost starts before first of autumn (Figs. 5 and 6). Higher elevation regions are
Fig. 5 Mild frost map of Fars province: a first frost occurrence at $50 \%$ probability, b last frost occurrence at $50 \%$ probability

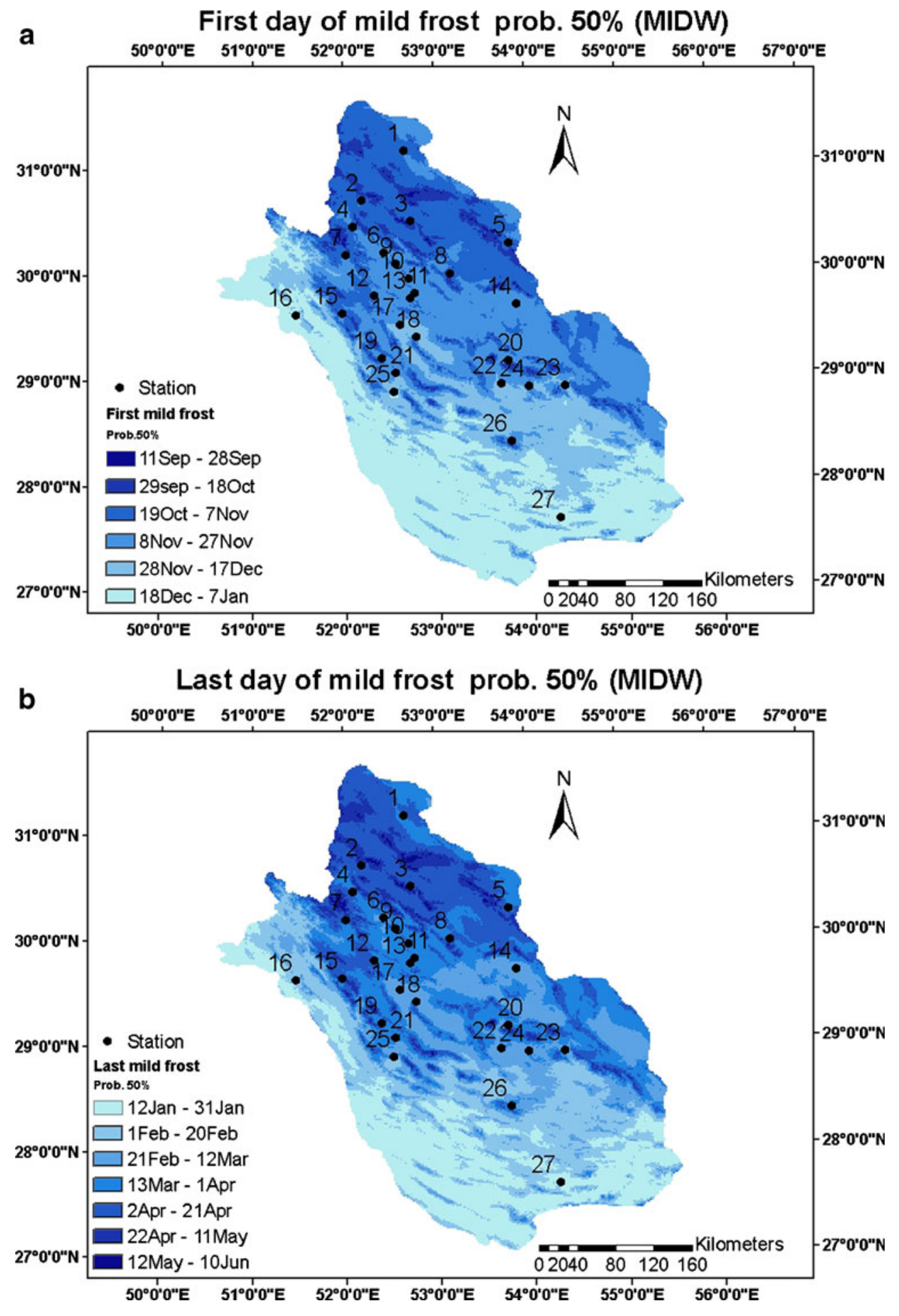


Fig. 6 Severe frost map of Fars province: a first frost occurrence at $50 \%$, b last frost occurrence at $50 \%$ probability
First day of severe frost prob. 50\% (MIDW)

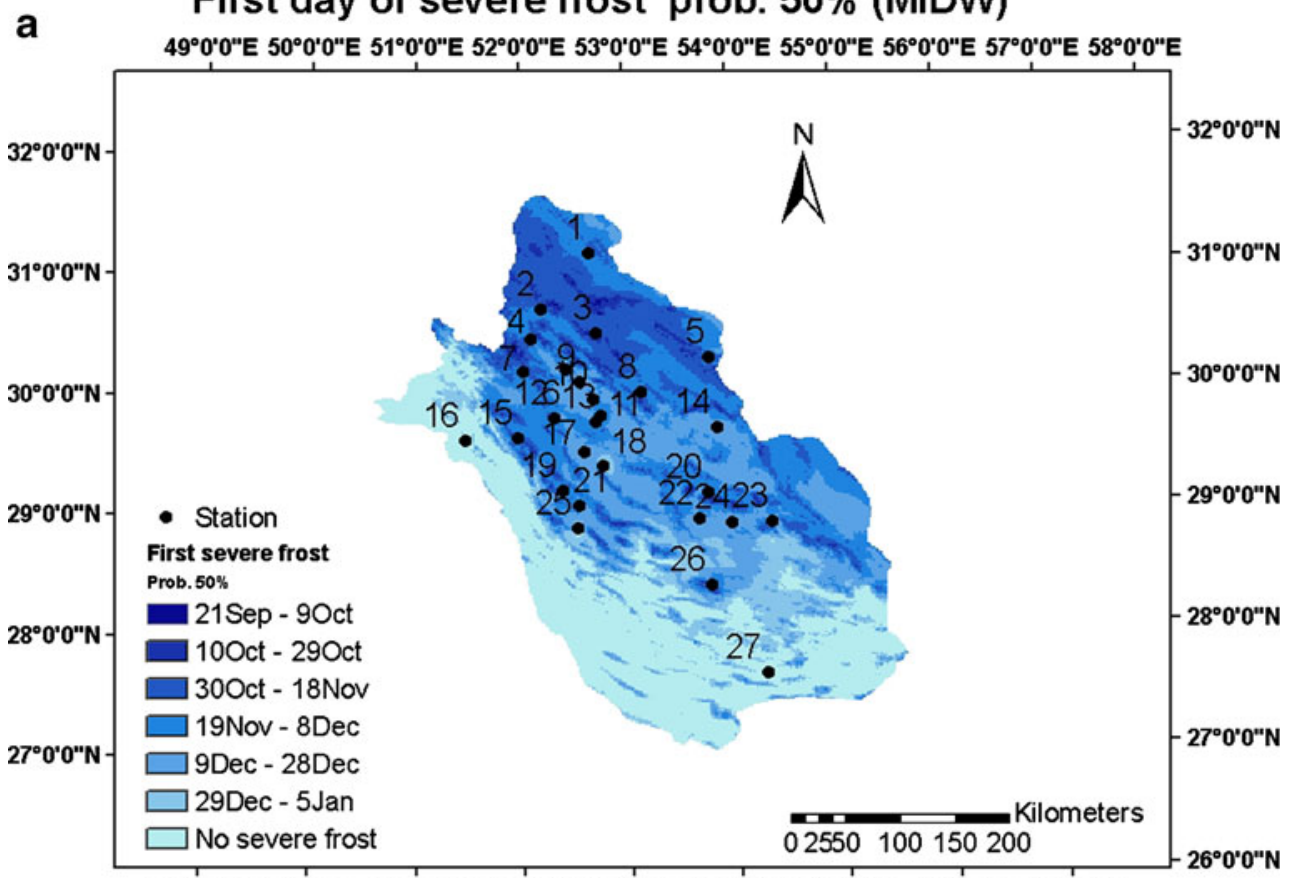

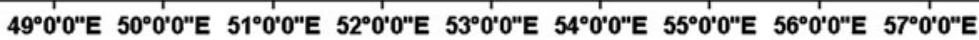

\section{Last day of severe frost prob. $50 \%$ (MIDW)}

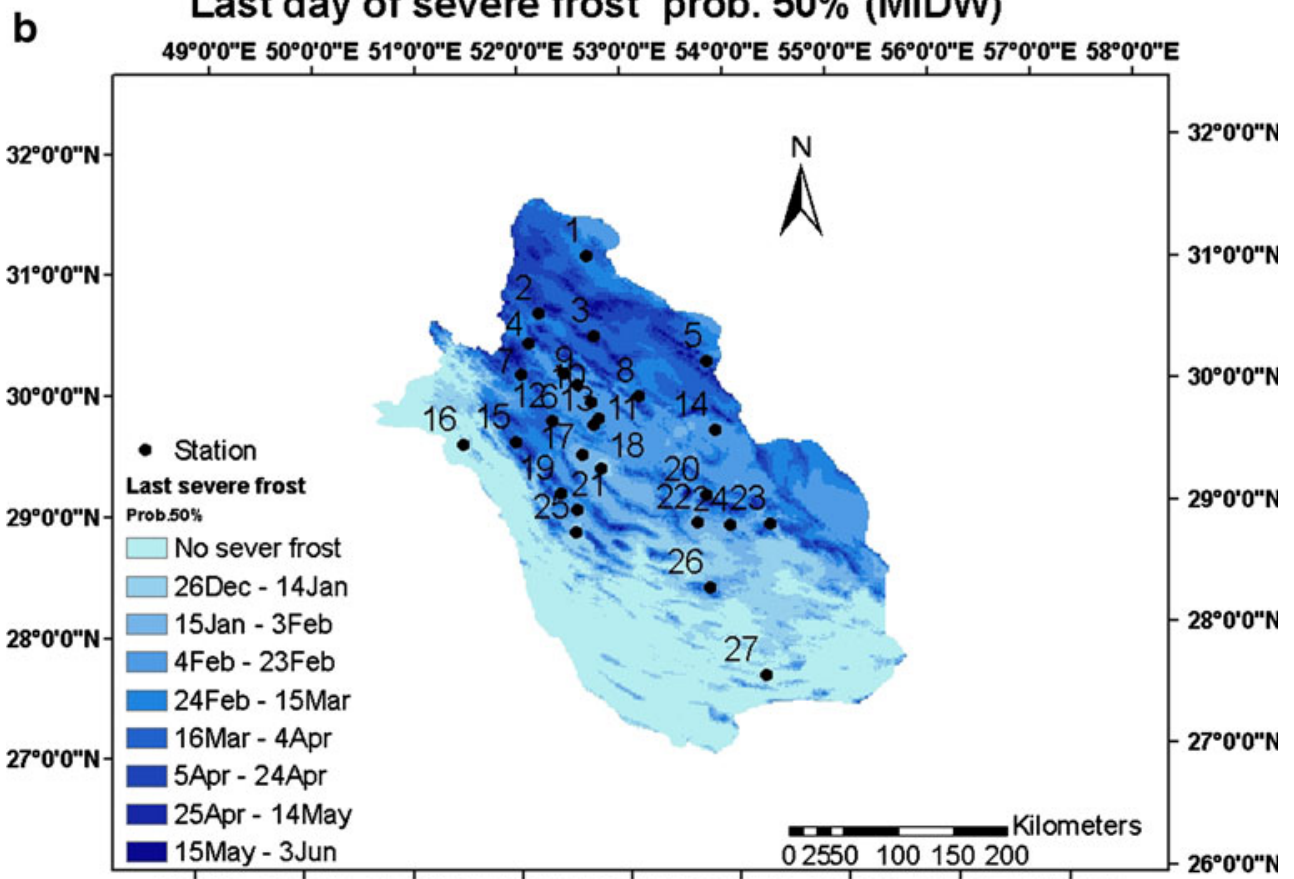

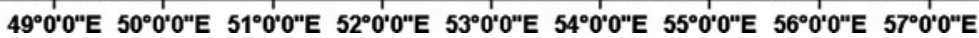

mostly located in the mountains, which are not suitable for agriculture. Therefore, these extrapolations would not cause any serious problem when preparing the maps. The maps of the first and last estimated mild and severe frost intensities at $50 \%$ probability for Fars province are shown in Figs. 4 and 5, respectively. According to these Figurers, in northern parts, the elevation is higher and frost events begin earlier and terminate later.

\section{Conclusions}

For preparation of frost atlas in Fars province, the minimum daily air temperatures at 27 meteorological stations were used. The values of minimum air temperature ranges of $0^{\circ} \mathrm{C}$ to $-1.5^{\circ} \mathrm{C},-1.5^{\circ} \mathrm{C}$ to $-3^{\circ} \mathrm{C}$, and below $-3^{\circ} \mathrm{C}$ were considered as mild, moderate, and severe frosts intensities, respectively. For Fars province, iso-occurrence days from 
the first of autumn for different frost intensities and occurrence probabilities $(25 \%, 50 \%, 75 \%$, and $90 \%)$ were estimated using ordinary kriging, cokriging, residual kriging type 1, residual kriging type 2, universal kriging, $I D W$, and $M I D W$ methods. In $M I D W$ method, the trends of the first and last days of frost dates were estimated using the relationship between frost dates and station elevation for different intensities and occurrence probabilities. The residual values (difference between measured and predicted dates) were estimated by $I D W$ method. The errors of estimation of frost dates by the $R K 2$ and the MIDW methods were smaller than the other applied methods, but in some cases, because of lack of establishment of a strong spatial structure in $R K 2$ method, the predictions were not acceptable. The method of $M I D W$, on the other hand, was much simpler and more reasonable for application. Therefore, it was selected for preparation of frost atlas in Fars province.

Open Access This article is distributed under the terms of the Creative Commons Attribution Noncommercial License which permits any noncommercial use, distribution, and reproduction in any medium, provided the original author(s) and source are credited.

\section{References}

Benavides R, Montes F, Rubio A, Osoro K (2007) Geostatistical modelling of air temperature in a mountainous region of Northern Spain. Agric For Meteorol 146:173-188

Blennow K (1993) Frost in July in a coastal area of southern Sweden. Weather 48:217-222

Blennow K (1998) Modeling minimum air temperature in partially and clear felled forest. Agric For Meteorol 91:223-235

Carrega P (1995) A method for reconstruction of mountain air temperatures with automatic cartographic applications. Theor Appl Climatol 52:69-84

Carrera-Hernandez JJ, Gaskin SJ (2007) Spatio temporal analysis of daily precipitation and temperature in the Basin of Mexico. J Hydrol 336:231-249

Chiles J, Delfiner P (1999) Geostatistics: Modeling Spatial Uncertainty. Wiley, New York, p 695

Dodson R, Marks D (1997) Daily air temperature interpolated at high spatial resolution over a large mountainous region. Clim Res 8:1-20
Francois C, Bosseno R, Vacher JJ, Seguin B (1999) Frost risk mapping derived from satellite and surface data over the Bolivian Altiplano. Agric For Meteorol 95:113-137

George Y, Lu W, Wong WD (2008) An adaptive inverse-distance weighting spatial interpolation technique. Comput Geosci 34:1044-1055

Goovaerts P (1997) Geostatistics for Natural Resources Evaluation. Oxford University Press, New York, p 483

Hudson G, Wackernagel H (1994) Mapping temperature using Kriging with external drift: theory and example from Scotland. Int J Clim 14:77-91

Isaaks EH, Srivastava RM (1989) An Introduction to Applied Geostatistics. Oxford University Press, New York, p 561

Johnston K, Ver Hoef JM, Krivoruchko K, Luca N (2001) Using Arcgis Geostatistical Analyst. ESRI, New York, 300p

Kitanidis PK (1997) Introduction to Geostatistics: Applications in Hydrogeology. Cambridge University Press, Cambridge, p 249p

Li BG, Ran Y, Cao J, Liu WX, Shen WR, Wang XJ, Raymond M, Coveney JR, Tao S (2007) Spatial structure analysis and kriging of dichlorodiphenyltrichloroethane residues in topsoil from Tianjin, China. Geoderma 141:71-77

Noshadi M, Sepaskhah AR (2005) Application of geostatistics for potential evapotranspiration estimation. Iran J Sci Technol Trans B 29:343-355

Reddy SJ (1983) Agroclimatic classification of the semiarid topics II. Identification of classificatory variables. Agric Meteorol 30:201219

Richardson AD, Lee X, Friedland AJ (2004) Microclimatology of treeline spruce-fir forests in mountains of the northeastern United States. Agric For Meteorol 125:53-66

Rolland C (2002) Spatial and seasonal variations of air temperature lapse rate in Alpine region. J Clim 16:1032-1046

Rosenberg NJ, Blade BL, Verma SB (1983) Microclimate. The biological environment. Wiley, New York, p 495

Rubio A, Sánchez O, Gómez V, Graña D, Elena R, Blanco A (2002) Autoecologi'a de los castañares de Castilla (España) (Autoecology of chestnut tree forest in Castilla, Spain). Investig Agraria: Sistemas de Recursos Forestales 11:373-393

Tait A, Zheng X (2002) Mapping frost occurrence using satellite data. J Appl Meteor 42:193-203

Ventskevich GZ (1985) Agrometeorology. Translated from Russian by the Israel Program for Scientific Translation for National Science Foundation. OTS. 60-51044

Wackernagel H (1998) Multivariate Geostatistics: An Introduction with Applications, 2nd edn. Springer, Berlin, p 291

Walpole RE, Mayers RH, Mayers SL (1998) Probability and statistics. Prentice Hall, Upper Saddle River, p 739

Weibull W (1951) A statistical distribution function of wide applicability. J Appl Mech Trans ASME 18(3):293-297

Whiteman TM (1957) Freezing points of fruits, vegetables and florist stocks. U.S. Dept. of Agric. Marketing Res. Report. No. 196. 32p 